\title{
Teor de clorofila e produtividade do feijoeiro em razão da adubação nitrogenada
}

\author{
Rogério Peres Soratto(1), Marco Antonio Camillo de Carvalho(2) e Orivaldo Arf ${ }^{(3)}$
}

(1)Universidade Estadual Paulista (Unesp), Fac. de Ciências Agronômicas, Campus de Botucatu, Caixa Postal 237, CEP 18603-970 Botucatu, SP. E-mail: soratto@fca.unesp.br (2)Universidade do Estado do Mato Grosso, Rod. MT 208, Km 147, Caixa Postal 324, CEP $78580-000$ Alta Foresta, MT. E-mail: marcocarra@bol.com.br (3)Unesp, Fac. de Engenharia, Campus de Ilha Solteira, Caixa Postal 31, CEP 15385-000 IIha Solteira, SP. E-mail: arf@agr.feis.unesp.br

\begin{abstract}
Resumo - Recomendações de adubação nitrogenada para o feijoeiro referem-se ao sistema de preparo convencional do solo, e pode ocorrer subestimação da necessidade da cultura em sistema de plantio direto, já que nesse sistema pode haver demanda de nitrogênio. O objetivo deste trabalho foi avaliar a resposta do feijoeiro (Phaseolus vulgaris $\mathrm{L}$.) a doses de $\mathrm{N}$, em dois sistemas de manejo do solo, como também a possibilidade de uso do teor de clorofila como indicativo do teor de $\mathrm{N}$ nas folhas. O delineamento experimental foi em blocos ao acaso, em esquema de parcela subdividida, com quatro repetições. As parcelas foram constituídas pelos sistemas de manejo do solo: plantio direto e preparo convencional (uma gradagem pesada + duas gradagens leves). Cinco doses de $\mathrm{N}\left(0,35,70,140\right.$ e $210 \mathrm{~kg} \mathrm{ha}^{-1}$, como uréia), aplicadas em cobertura, constituíram as subparcelas. $\mathrm{O}$ feijoeiro demonstrou maior necessidade de $\mathrm{N}$ quando cultivado em plantio direto do que no sistema convencional de preparo do solo. $\mathrm{O}$ sistema de plantio direto do feijoeiro proporcionou maior eficiência na utilização do $\mathrm{N}$ aplicado em cobertura, acarretando maior produtividade por unidade do nutriente aplicado em relação ao sistema convencional. A avaliação indireta do teor de clorofila mostrou-se viável em indicar o estado nutricional de $\mathrm{N}$ do feijoeiro, em ambos sistemas de manejo.
\end{abstract}

Termos para indexação: Phaseolus vulgaris, plantio direto, preparo convencional, nitrogênio, adubação de cobertura.

\section{Chlorophyll content and grain yield of common bean as affected by nitrogen fertilization}

\begin{abstract}
Nitrogen fertilizer recommendations for common bean crop regard conventional tillage, which may underestimate the crop necessity in no-tillage system, because greater demand for nitrogen can occur in this system. The objective of this work was to evaluate the performance of common bean (Phaseolus vulgaris L.) affected by different nitrogen levels on two management soil systems, as well as to verify the possibility on the use of chlorophyll content as an indicative of $\mathrm{N}$ content in leaves. A randomized complete block design, in splitplot scheme with four replications, was used. The plots were constituted by management soil systems: notillage and conventional tillage (one disk harrow + two levelling harrow). Five $\mathrm{N}$ levels $(0,35,70,140$, and $210 \mathrm{~kg} \mathrm{ha}^{-1}$, as urea) sidedressing fertilization constituted the subplots. Common bean crop grown in no-tillage system demanded more $\mathrm{N}$ than in conventional tillage system. No-tillage system provided greater sidedressing $\mathrm{N}$ use efficiency by common bean crop, causing greater yield by each nutrient unit applied than the conventional tillage system. The indirect measurement of chlorophyll content was feasible for indicating the common bean $\mathrm{N}$ nutritional status, in both management soil systems.
\end{abstract}

Index terms: Phaseolus vulgaris, no-tillage, conventional tillage, nitrogen, sidedressing fertilization.

\section{Introdução}

O preparo do solo tem como objetivo principal controlar plantas daninhas e favorecer o desenvolvimento e a produtividade das culturas. No entanto, o uso intensivo do solo pode predispô-lo à formação de camadas compactadas, à redução da estabilidade dos agregados e ao aumento da erosão.
O sistema de plantio direto propicia, principalmente na camada superficial, maior estabilidade estrutural, menor porosidade total e macroporosidade, em relação ao sistema convencional (Corrêa, 1985). Assim, aliando-se a estabilidade estrutural à manutenção dos resíduos culturais na superfície do solo, tem-se maior proteção contra o impacto direto das gotas de chuva, além do favorecimento da infiltração e da redução da perda de água 
por escoamento superficial por causa da não formação de crostas e da maior rugosidade superficial (Stone \& Silveira, 1999). Esse sistema reduz significativamente as perdas de solo por erosão, com conseqüente melhoria das condições físicas, químicas e biológicas do solo, que irão repercutir na sua fertilidade (Wutke, 1993). Além disso, fatores como temperatura e cobertura superficial têm, em muitas situações, disponibilizado mais água às plantas em solos sob plantio direto, influenciando diretamente a economia de água, o desenvolvimento e a produtividade das culturas (Stone \& Silveira, 1999; Andrade et al., 2002).

No entanto, pelo fato de os resíduos vegetais permanecerem na superfície do solo, a taxa de mineralização da matéria orgânica é mais lenta, comparada com o sistema convencional, em que há incorporação dos resíduos (Merten \& Fernandes, 1998; Gonçalves \& Ceretta, 1999), o que tem provocado maior demanda de N, principalmente no início do sistema (Balbino et al., 1996; Soratto et al., 2001). Em virtude da manutenção da água no solo, o sistema de plantio direto pode contribuir para a maior eficiência de utilização do $\mathrm{N}$ aplicado em cobertura, pois o nitrato entra em contato com as raízes por fluxo de massa (Rosolem, 1996).

$\mathrm{O} \mathrm{N}$ é o nutriente absorvido em quantidades mais elevadas pelo feijoeiro e, conseqüentemente, a sua deficiencia é mais freqüente (Oliveira et al., 1996). Plantas com deficiência desse elemento apresentam-se atrofiadas e as folhas revelam coloração entre verdepálido e amarela, que se inicia pelas folhas mais velhas e relaciona-se com a participação do $\mathrm{N}$ na estrutura da molécula de clorofila (Oliveira et al., 1996). Além disso, a deficiência de $\mathrm{N}$ provoca mudanças na resistência difusiva do $\mathrm{CO}_{2}$, em virtude do aumento na resistência do mesófilo e em menor proporção na resistência estomática (Ryle \& Hesketh, 1969), alterando a síntese e atividade da ribulose 1,5 bisfosfato carboxilaseoxigenase (Rubisco), o que provoca redução nas taxas fotossintéticas (Costa et al., 1988), com consequiências no desenvolvimento e produtividade das culturas.

A maioria das recomendações de adubação nitrogenada para o feijoeiro é direcionada ao sistema de preparo convencional. Carvalho et al. (1992) recomendam $90 \mathrm{~kg} \mathrm{ha}^{-1}$ de $\mathrm{N}$ para alcançar a produtividade máxima. Já Silveira \& Damasceno (1993) recomendam apenas $72 \mathrm{~kg} \mathrm{ha}^{-1}$ de $\mathrm{N}$ para maximizar a produtividade do feijoeiro. Silva et al. (2000), em sistema de preparo convencional, obtiveram resposta quadrática do feijoeiro ao $\mathrm{N}$ e a produtividade máxima foi alcançada com $74 \mathrm{~kg} \mathrm{ha}^{-1}$ de nitrogênio. Por outro lado, no mesmo tipo de solo, sob sistema de plantio direto, Soratto et al. (2001) e Silva (2002) verificaram resposta linear da produtividade até a dose máxima testada, ou seja, 100 e $150 \mathrm{~kg} \mathrm{ha}^{-1}$, respectivamente. Como os cultivos foram realizados em sucessão a gramíneas, a elevada quantidade de $\mathrm{N}$ exigida está relacionada à necessidade dos microrganismos presentes no solo. Essa grande quantidade de $\mathrm{N}$ é utilizada pelos microrganismos na decomposição dos restos culturais, de alta relação $\mathrm{C} / \mathrm{N}$, competindo, portanto, com o feijoeiro. Esses resultados subsidiam os pressupostos da necessidade de maiores quantidades de $\mathrm{N}$ para $\mathrm{o}$ feijoeiro em sistema de plantio direto (Carvalho et al., 2003). Além do que, sob condições de menor estresse hídrico, proporcionado por esse sistema (Stone \& Silveira, 1999; Andrade et al., 2002), o feijoeiro pode apresentar melhor eficiência de utilização do $\mathrm{N}$ aplicado em cobertura (Costa et al., 1988).

Como o N é constituinte da molécula de clorofila, geralmente existe alta correlação entre o seu teor e a clorofila nas folhas do feijoeiro. Dessa forma, vários autores têm relatado a viabilidade de se utilizar a avaliação indireta de clorofila como indicativo do estado nutricional em relação ao N (Furlani Junior et al., 1996; Carvalho et al., 2003; Silveira et al., 2003).

O objetivo deste trabalho foi avaliar a resposta do feijoeiro a doses de $\mathrm{N}$, em dois sistemas de manejo do solo, como também verificar a possibilidade de uso do teor de clorofila com indicativo do teor de $\mathrm{N}$ nas folhas.

\section{Material e Métodos}

O trabalho foi realizado na área experimental da $\mathrm{Fa}-$ culdade de Engenharia de Ilha Solteira - Unesp, Município de Selvíria, MS (51 $22^{\prime} \mathrm{W}$ e $20^{\circ} 22^{\prime} \mathrm{S} ; 335 \mathrm{~m}$ de altitude). O solo é um Latossolo Vermelho distrófico, típico, argiloso (Embrapa, 1999). O clima, conforme a classificação de Köppen, é do tipo Aw, com precipitação média anual de $1.370 \mathrm{~mm}$, concentrada de outubro a março; a temperatura média anual do ar é de $23,5^{\circ} \mathrm{Ce}$ a umidade relativa do ar situa-se entre $70 \%$ e $80 \%$ (média anual).

Antes da instalação do experimento, foram coletadas amostras compostas de 20 subamostras, na camada de 0-0,20 m, para a determinação das características químicas, realizadas de acordo com Raij \& Quaggio (1983), cujos resultados foram: matéria orgânica $24,0 \mathrm{~g} \mathrm{dm}^{-3}$; 
$\mathrm{pH}\left(\mathrm{CaCl}_{2}\right)$ 5,3; $\mathrm{P}$ (resina), 18,0 $\mathrm{mg} \mathrm{dm}^{-3} ; \mathrm{K}, \mathrm{Ca}$ e $\mathrm{Mg}$, 2,2, 33,0 e 14,0 $\mathrm{mmol}_{\mathrm{C}} \mathrm{dm}^{-3}$, respectivamente, e saturação por bases, $64 \%$.

O delineamento experimental utilizado foi o de blocos ao acaso, com parcelas subdivididas e quatro repetições. As parcelas foram constituídas por dois sistemas de manejo do solo - plantio direto e preparo convencional - e as subparcelas, por cinco doses de N, 0, 35, 70, 140 e $210 \mathrm{~kg} \mathrm{ha}^{-1}$, aplicadas em cobertura aos 20 dias após a emergência das plântulas, tendo como fonte a uréia. Cada subparcela era constituída de seis linhas de $5 \mathrm{~m}$ de comprimento. A área útil foi constituída pelas quatro linhas centrais, desprezando-se $0,50 \mathrm{~m}$ em ambas as extremidades de cada linha.

$\mathrm{O}$ experimento foi instalado em área anteriormente cultivada com milho no verão. No tratamento com preparo convencional do solo, utilizou-se grade pesada na profundidade de $0,15-0,20 \mathrm{~m}$, seguida de duas gradagens com grade leve na profundidade de $0,10-0,12 \mathrm{~m}$, sendo a última realizada às vésperas da semeadura. No tratamento com plantio direto, implantado na safra de verão anterior, com a cultura do milho, a dessecação da cobertura vegetal do solo foi realizada mediante a aplicação de $1.560 \mathrm{~g} \mathrm{ha}^{-1}$ do i.a. de glifosate.

A semeadura foi realizada em 27/6/2000, utilizando a cultivar IAC Carioca com espaçamento de $0,45 \mathrm{~m}$ entre linhas e 13 sementes por metro. Pouco antes da semeadura, as sementes foram tratadas com o fungicida benomyl (100 g do i.a. por $100 \mathrm{~kg}$ de sementes). Por ocasião da semeadura, aplicaram-se, em todos os tratamentos, $240 \mathrm{~kg} \mathrm{ha}^{-1}$ da fórmula 8-28-16 de NPK. As irrigações foram realizadas por meio de aspersão com pivô central, durante todo o ciclo da cultura. Após a aplicação de $\mathrm{N}$ em cobertura, aplicou-se em todo o experimento, uma lâmina d'água de $5 \mathrm{~mm}$, visando minimizar as perdas por volatilização. $\mathrm{O}$ controle das plantas daninhas foi realizado mediante duas aplicações seqüenciais do herbicida fluazifop-p-butil + fomesafen $\left(100+125 \mathrm{~g}\right.$ do i.a. ha $\left.{ }^{-1}\right)$. Durante o desenvolvimento da cultura, foram realizados os demais tratos culturais e fitossanitários recomendados.

Por ocasião do florescimento pleno, realizou-se a leitura indireta de clorofila, com o aparelho Minolta SPAD502, na primeira folha completamente desenvolvida, média de dez leituras por folíolo, em cinco plantas por parcela. Os dados de leitura foram transformados em teor de clorofila $\left(\mathrm{mg} \mathrm{dm}^{-2}\right)$ pela equação y $=-0,152+$ 0,0996x (Barnes et al., 1992). O teor de $\mathrm{N}$ total nas fo- lhas foi determinado usando-se as mesmas folhas coletadas após a leitura de clorofila, imediatamente destacadas e acondicionadas em sacos de papel e secadas em estufa com circulação forçada de ar a $65^{\circ} \mathrm{C}$, por 72 horas, moídas e submetidas à análise, conforme Malavolta et al. (1997). Foram coletadas dez plantas de cada parcela e determinados o número de vagens/planta, o número de grãos/vagem e a massa de 100 grãos. Em duas fileiras da área útil de cada subparcela, as plantas foram arrancadas e deixadas a secar em pleno sol e em seguida submetidas à trilha manual; a umidade dos grãos foi corrigida para $0,13 \mathrm{~kg} \mathrm{~kg}^{-1}$ (base úmida), obtendo-se a produtividade de grãos.

Os resultados foram submetidos à análise de variância. As médias dos sistemas de manejo do solo foram comparadas pelo teste DMS a 5\% de probabilidade, enquanto os efeitos das doses de $\mathrm{N}$ foram avaliados por meio de análise de regressão, adotando-se como critério para escolha do modelo a magnitude dos coeficientes de regressão significativos a $5 \%$ de probabilidade pelo teste t. Foram realizadas análises de correlação simples entre as características agronômicas do feijoeiro e determinou-se também o fator $\mathrm{N}$, que é o fator de utilização do $\mathrm{N}$ aplicado, mediante a relação $\mathrm{kg} \mathrm{ha}^{-1} \mathrm{de} \mathrm{N} / \mathrm{kg} \mathrm{ha}^{-1} \mathrm{da}$ produtividade incrementada, em relação à testemunha (sem aplicação de $\mathrm{N}$ ) em ambos os sistemas de manejo do solo.

\section{Resultados e Discussão}

A aplicação de $\mathrm{N}$ em cobertura proporcionou aumentos no teor de $\mathrm{N}$ nas folhas do feijoeiro, em ambos os sistemas de manejo do solo (Figura 1). No sistema de preparo convencional a resposta foi quadrática e o maior teor de $\mathrm{N}$ nas folhas do feijoeiro foi alcançado com a dose estimada de $185 \mathrm{~kg} \mathrm{ha}^{-1}$ de nitrogênio. Já no sistema de plantio direto, houve efeito linear da adubação nitrogenada de cobertura sobre o teor de $\mathrm{N}$ da folha, indicando que mesmo a maior dose utilizada $\left(210 \mathrm{~kg} \mathrm{ha}^{-1}\right)$ não foi suficiente para fornecer todo $\mathrm{o} \mathrm{N}$ requerido pela cultura, apesar de os teores de todos os tratamentos estarem dentro da faixa considerada adequada para o feijoeiro (30-50 $\mathrm{g} \mathrm{kg}^{-1}$ ), conforme Malavolta et al. (1997). Os resultados confirmam a hipótese de que, no sistema de plantio direto, existe menor disponibilidade de $\mathrm{N}$ às plantas, em relação ao sistema com incorporação dos resíduos, devido à imobilização do nutriente, principalmente quando os resíduos culturais presentes 
na superfície do solo possuem alta relação C/N, como é o caso do milho (Gonçalves \& Ceretta, 1999).

Incrementos na dose de $\mathrm{N}$ em cobertura provocaram aumento do teor de clorofila, com respostas semelhantes e quadráticas em ambos os sistemas de manejo do solo (Figura 1). Independentemente do sistema de manejo do solo, o teor de $\mathrm{N}$ nas folhas apresentou correlação alta e significativa com o teor de clorofila do feijoeiro (Figura 2), o que é justificado pelo fato desse elemento fazer parte da molécula de clorofila (Malavolta et al.,
1997). Além disso, a alta correlação entre o teor de $\mathrm{N} \mathrm{e}$ de clorofila nas folhas do feijoeiro evidencia a possibilidade da utilização da prática não destrutiva de medição indireta da clorofila, por meio do clorofilômetro portátil, para estimar a necessidade de $\mathrm{N}$ pelo feijoeiro (Furlani Junior et al., 1996; Carvalho et al., 2003). No entanto, em ambos os sistemas de manejo do solo, os teores máximos de clorofila seriam atingidos com a dose estimada de aproximadamente $165 \mathrm{~kg} \mathrm{ha}^{-1} \mathrm{de} \mathrm{N}$, a qual está abaixo da verificada na obtenção dos maiores teores de
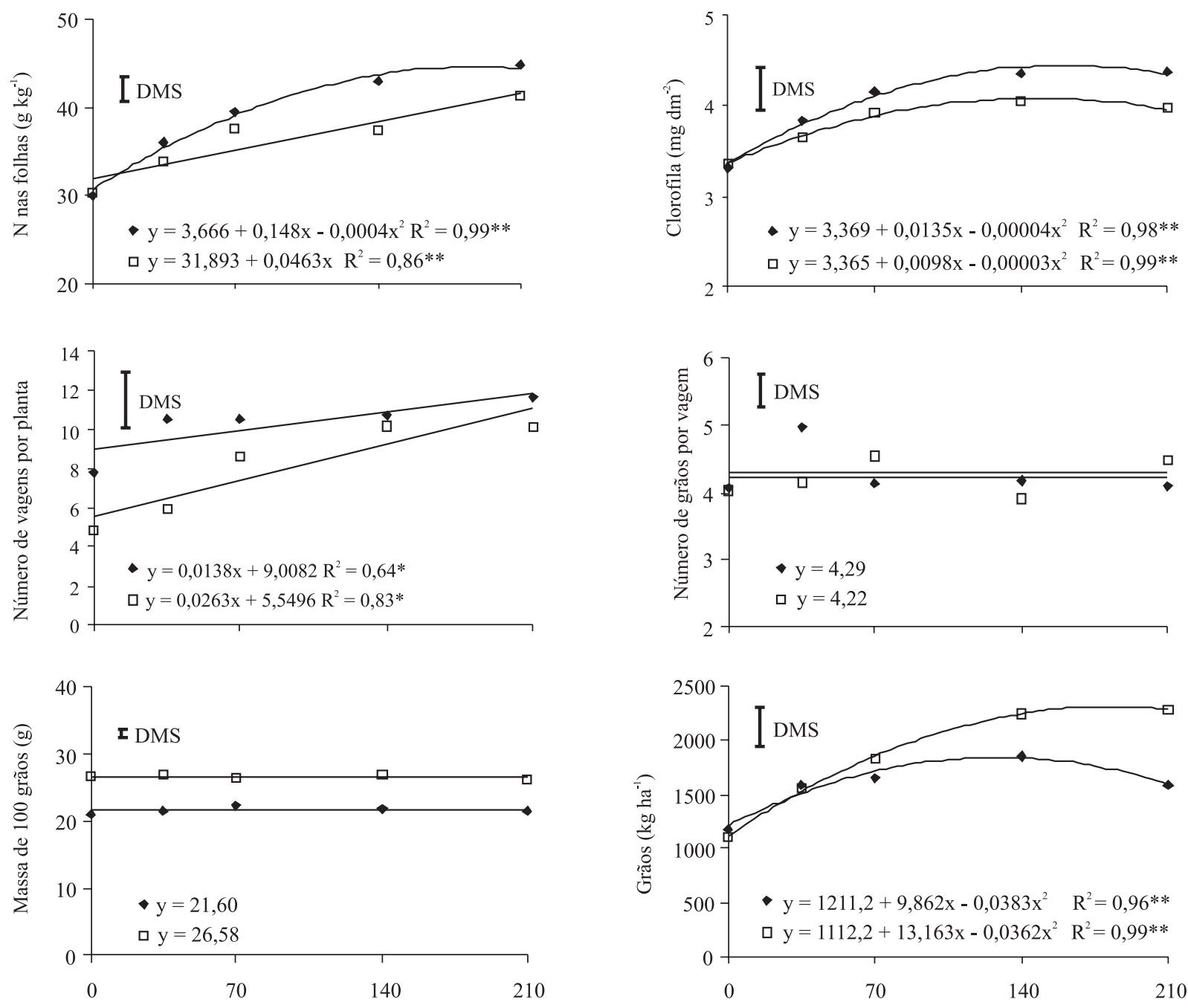

Nitrogênio em cobertura $\left(\mathrm{kg} \mathrm{ha}^{-1}\right)$

Figura 1. Teor de nitrogênio nas folhas, teor de clorofila, número de vagens por planta, número de grãos por vagem, massa de 100 grãos e produtividade de grãos do feijoeiro em função de doses de nitrogênio aplicadas em cobertura, em sistema de plantio direto ( $\square$ ) e preparo convencional do solo $(\bullet)$ * e**Significativo a $5 \%$ e a $1 \%$ de probabilidade pelo teste t, respectivamente. Barras verticais indicam o valor de DMS a 5\% de probabilidade. 
$\mathrm{N}$ nas folhas. Dessa forma, os resultados evidenciam que maiores doses de $\mathrm{N}$ disponíveis no solo aumentaram o teor do pigmento, até certo ponto, indicando a não produção de clorofila pelas plantas além da quantidade de que necessitam, ou que outros fatores podem ter limitado o aumento do teor de clorofila.

Quanto ao número de vagens por planta, houve efeito linear crescente em razão da aplicação de $\mathrm{N}$ em ambos os sistemas de manejo do solo (Figura 1). $\mathrm{Na}$ ausência de aplicação de $\mathrm{N}$, assim como com a utilização da menor dose de $\mathrm{N}$ em cobertura $\left(35 \mathrm{~kg} \mathrm{ha}^{-1}\right)$, o sistema de preparo convencional proporcionou maior número de vagens por planta, em comparação com o plantio direto.

No sistema de preparo convencional, a demanda por $\mathrm{N}$ é menor, devido à maior disponibilização do nutriente por meio do processo de mineralização, que é acelerado pela incorporação dos restos culturais característicos desse sistema de manejo. No sistema de plantio direto, os acréscimos no número de vagens por planta em razão da aplicação de $\mathrm{N}$ foram maiores, o que pode ser explicado pela maior demanda de $\mathrm{N}$ na fase inicial. Essa maior demanda se justifica pela insuficiente quantidade de nutriente que o solo fornece às plantas, decorrente da lenta taxa de mineralização da matéria orgânica, advinda dos restos culturais na superfície do solo (Merten \& Fernandes, 1998; Gonçalves \& Ceretta, 1999). O número de vagens por planta sofre grande influência da adubação nitrogenada, e, quando a planta apresenta deficiência desse nutriente, produz menos flores e, con-

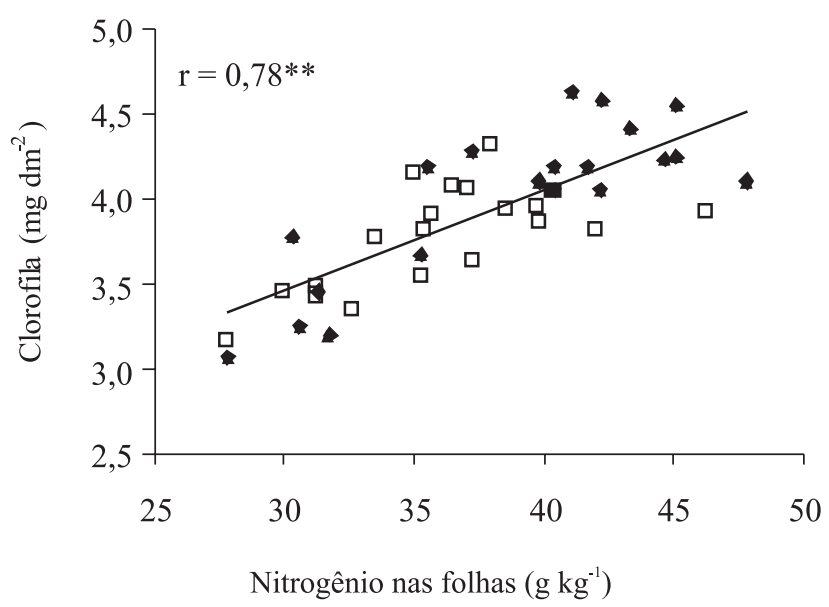

Figura 2. Correlação entre teor de clorofila e de nitrogênio nas folhas do feijoeiro, em sistema de plantio direto $(\square)$ e preparo convencional do solo $(\diamond)$. $* *$ Significativo a $1 \%$ de probabilidade pelo teste $\mathrm{t}$. seqüentemente, menos vagens (Portes, 1996). Portanto, os resultados indicam a necessidade da utilização de maiores doses de $\mathrm{N}$ no sistema de plantio direto.

Outro fator que influencia na resposta constatada no sistema de plantio direto é o maior teor de água no solo, o que pode ter aumentado a taxa fotossintética, por contribuir na redução da resistência estomática e do mesófilo, além de favorecer a síntese e a atividade da Rubisco (Costa et al., 1988), já que houve maior correlação entre o teor de clorofila nas folhas e o número de vagens por planta nesse sistema (Figura 3).

O número de grãos por vagem não foi influenciado pelos fatores estudados (Figura 1), o que se justifica pelo fato de esta característica apresentar alta herdabilidade genética, sendo pouco influenciada pelo
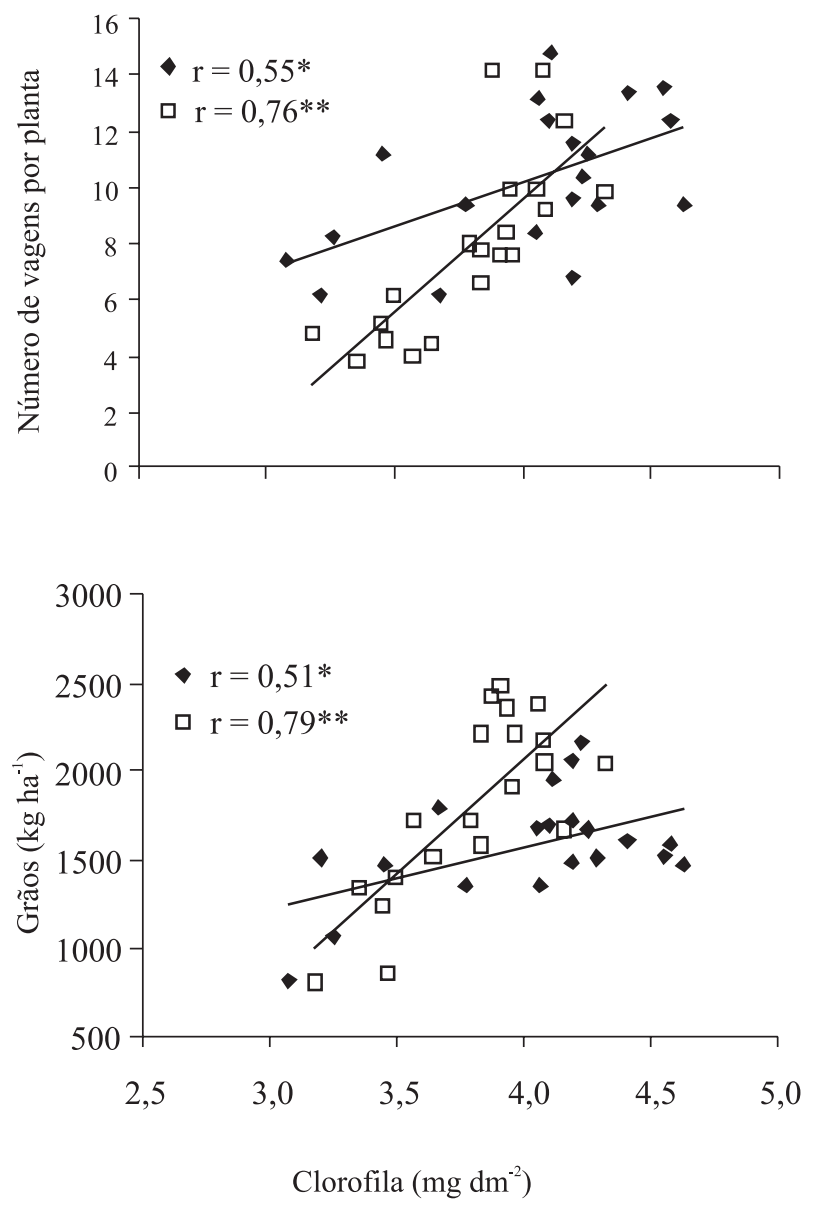

Figura 3. Correlações entre teor de clorofila nas folhas e número de vagens por planta, e a produtividade do feijoeiro, em sistema de plantio direto $(\square)$ e preparo convencional do solo $(\diamond)$. $\mathrm{e}^{* *}$ Significativo a 5 e a $1 \%$ de probabilidade pelo teste $\mathrm{t}$, respectivamente. 
ambiente (Andrade et al., 1998). Além disso, esta característica geralmente não apresenta correlação com a produtividade, como verificado.

A massa de 100 grãos sofreu efeito apenas do sistema de manejo do solo, sendo que, independentemente da dose de $\mathrm{N}$ aplicada em cobertura, o sistema de plantio direto proporcionou maiores valores de massa (Figura 1). A provável manutenção de maior quantidade de água disponível às plantas no sistema de plantio direto pode ter contribuído para o melhor enchimento de grãos. A massa de 100 grãos correlacionou-se positivamente com a produtividade de grãos, indicando que os maiores valores dessa variável, proporcionados pelo plantio direto, contribuíram na obtenção de maior produtividade.

Houve efeito quadrático na produtividade de grãos devido à aplicação de $\mathrm{N}$, em ambos os sistemas de manejo do solo (Figura 1). No sistema de preparo convencional, a produtividade máxima foi alcançada com a dose estimada de $129 \mathrm{~kg} \mathrm{ha}^{-1}$ de $\mathrm{N}$ em cobertura, enquanto no sistema de plantio direto, a dose estimada foi de $182 \mathrm{~kg} \mathrm{ha}^{-1}$ de nitrogênio. Neste sistema, a aplicação de doses mais elevadas de $\mathrm{N}$ proporcionou maiores produtividades, comparado ao sistema convencional de preparo do solo. Apesar de os teores de clorofila terem se correlacionado semelhantemente com os teores de $\mathrm{N}$ em ambos os sistemas de manejo do solo (Figura 2), valores similares nos teores de clorofila correlacionaram-se com maiores valores do número de vagens por planta e, conseqüentemente, com maiores produtividades de grãos no sistema de plantio direto, em comparação ao preparo convencional (Figura 3). Assim, infere-se que a maior produtividade proporcionada pela utilização de elevadas doses de $\mathrm{N}$, no sistema de plantio direto, está associada ao melhor aproveitamento do $\mathrm{N}$ absorvido. Isto possivelmente ocorre em função da manutenção de maior quantidade de água no solo, decorrente da maior infiltração e menor evapotranspiração proporcionada pela cobertura do solo sob esse sistema de manejo (Stone \& Silveira, 1999; Andrade et al., 2002), o que pode ter favorecido a fotossíntese e o transporte de fotoassimilados. Costa et al. (1988) verificaram maior resposta do feijoeiro ao $\mathrm{N}$, quando submetido a maiores níveis de disponibilidade hídrica.

$\mathrm{O}$ incremento na dose de $\mathrm{N}$ aumentou o fator de utilização do $\mathrm{N}$ nos dois sistemas de manejo do solo, ou seja, diminuiu a eficiência da adubação nitrogenada (Tabela 1). No entanto, a eficiência de utilização do $\mathrm{N}$ foi maior no sistema de plantio direto, principalmente com a utilização de doses mais elevadas, que aumentaram a produtividade em aproximadamente três vezes, quando comparada ao sistema de preparo convencional (Figuras 1 e 3).

$\mathrm{O}$ feijoeiro em sistema de plantio direto apresentou maior resposta ao $\mathrm{N}$ aplicado em cobertura, confirmando a hipótese de que nesse sistema a aplicação de doses de $\mathrm{N}$ mais elevadas pode proporcionar maiores produtividades, quando comparado com o cultivo sob preparo convencional. Independentemente do sistema de manejo do solo, a técnica da avaliação indireta do teor de clorofila mostrou-se promissora para estimar o estado nutricional de $\mathrm{N}$ no feijoeiro, necessitando de pesquisas específicas para calibração do método, corroborando os resultados de Furlani Junior et al. (1996), Carvalho et al. (2003) e Silveira et al. (2003).

\section{Conclusões}

1. O feijoeiro exige mais $\mathrm{N}$ no sistema de plantio direto do que no sistema convencional de preparo do solo.

2. A eficiência do feijoeiro em utilizar o $\mathrm{N}$ aplicado em cobertura é maior no sistema de plantio direto, acarretando maior incremento na produtividade por unidade do nutriente aplicado.

Tabela 1. Aumento da produtividade de grãos do feijoeiro e fator de utilização do nitrogênio, considerando as doses de nitrogênio aplicadas em cobertura, em sistema de plantio direto e preparo convencional do solo.

\begin{tabular}{|c|c|c|c|c|}
\hline \multirow{2}{*}{$\begin{array}{c}\mathrm{N} \\
\left(\mathrm{kg} \mathrm{ha}^{-1}\right)\end{array}$} & \multicolumn{2}{|l|}{ Preparo convencional } & \multicolumn{2}{|l|}{ Plantio direto } \\
\hline & Aumento da produtividade ${ }^{(1)}\left(\mathrm{kg} \mathrm{ha}^{-1}\right)$ & Fator $\mathrm{N}^{(2)}$ & Aumento da produtividade $\left(\mathrm{kg} \mathrm{ha}^{-1}\right)$ & Fator $\mathrm{N}$ \\
\hline 35 & 397 & 0,088 & 463 & 0,076 \\
\hline 70 & 471 & 0,149 & 728 & 0,096 \\
\hline 140 & 668 & 0,210 & 1.152 & 0,122 \\
\hline 210 & 406 & 0,517 & 1.179 & 0,178 \\
\hline
\end{tabular}

(1) Obtido em relação à média de produtividade na testemunha (preparo convencional $=1.185 \mathrm{~kg} \mathrm{ha}^{-1}$ e plantio direto $=1.100 \mathrm{~kg} \mathrm{ha}^{-1}$ ). ${ }^{(2)}$ Fator de utilização do $\mathrm{N}$ : $\mathrm{kg} \mathrm{ha}^{-1}$ de $\mathrm{N} / \mathrm{kg} \mathrm{ha}^{-1}$ de produtividade aumentada. 
3. A avaliação indireta do teor de clorofila é eficiente para indicar o estado nutricional do feijoeiro quanto ao $\mathrm{N}$, em ambos os sistemas de manejo do solo.

\section{Agradecimentos}

À Fapesp, pela concessão de bolsa a Rogério Peres Soratto; ao CNPq, pela concessão de bolsa a Orivaldo Arf.

\section{Referências}

ANDRADE, M.J.B.; DINIZ, A.R.; CARVALHO, J.G. de; LIMA, S.F. Resposta da cultura do feijoeiro à aplicação foliar de molibdênio e às adubações nitrogenadas de plantio e cobertura. Ciência e Agrotecnologia, v.22, p.499-508, 1998.

ANDRADE, R. da S.; MOREIRA, J.A.A.; STONE, L.F.; CARVALHO, J. de A. Consumo relativo de água do feijoeiro no plantio direto em função da porcentagem de cobertura morta do solo. Revista Brasileira de Engenharia Agrícola e Ambiental, v.6, p.35-38, 2002.

BALBINO, L.C.; MOREIRA, J.A.A.; SILVA, J.G. da; OLIVEIRA, E.F.; OLIVEIRA, I.P. Plantio direto. In: ARAÚJO, R.S.; RAVA, C.A.; STONE, L.F.; ZIMMERMANN, M.J. de O. (Coord.). Cultura do feijoeiro comum no Brasil. Piracicaba: Potafos, 1996. p.301-352.

BARNES, J.D.; BALAGUER, L.; MANRIQUE, E.; ELVIRA, S.; DAVISON, A.W. A reappraisal of the use of DMSO for the extraction and determination of chlorophylls a and $\mathrm{b}$ in lichens and higher plants. Environmental and Experimental Botany, v.32, p.85-100, 1992.

CARVALHO, A.M. de; SILVA, A.M. da; COSTA, E.F. da; COUTO, L. Influência da fertirrigação no rendimento de grãos e componentes de produção do feijoeiro comum (Phaseolus vulgaris L.) cv. Carioca. Ciência e Prática, v.16, p.503-511, 1992.

CARVALHO, M.A.C. de; FURLANI JUNIOR, E.; ARF, O.; SÁ, M.E.; PAULINO, H.B.; BUZETTI, S. Doses e épocas de aplicação de nitrogênio e teores foliares deste nutriente e de clorofila em feijoeiro. Revista Brasileira de Ciência do Solo, v.27, p.445-450, 2003.

CORRÊA, J.C. Efeito de métodos de cultivo em algumas propriedades físicas de um Latossolo Amarelo muito argiloso do Estado do Amazonas. Pesquisa Agropecuária Brasileira, v.20, p.1317-1322, 1985.

COSTA, R.C.L. da; LOPES, N.F.; OLIVA, M.A.; BARROS, N.F. de. Efeito da água e do nitrogênio sobre a fotossíntese, respiração e resistência estomática em Phaseolus vulgaris. Pesquisa Agropecuária Brasileira, v.23, p.1371-1379, 1988.

EMBRAPA. Centro Nacional de Pesquisa de Solos (Rio de Janeiro, RJ). Sistema Brasileiro de Classificação dos Solos. Rio de Janeiro: Embrapa-SPI; Embrapa-CNPS, 1999. 412p.

FURLANI JUNIOR, E.; NAKAGAWA, J.; BULHÕES, L.J.; MOREIRA, J.A.A.; GRASSI FILHO, H. Correlação entre leituras de clorofila e níveis de nitrogênio aplicados em feijoeiro. Bragantia, v.55, p.171-175, 1996.

GONÇALVES, C.N.; CERETTA, C.A. Plantas de cobertura de solo antecedendo o milho e seu efeito sobre o carbono orgânico do solo, sob plantio direto. Revista Brasileira de Ciência do Solo, v.23, p.307-313, 1999.

MALAVOLTA, E.; VITTI, G.C.; OLIVEIRA, S.A. Avaliação do estado nutricional das plantas: princípios e aplicações. 2.ed. Piracicaba: Potafos, 1997. 319p.

MERTEN, G.H.; FERNANDES, F.F. Manejo do solo de baixa aptidão. In: DAROLT, M.R. (Org.). Plantio direto: pequena propriedade sustentável. Londrina: Iapar, 1998. p.43-64. (Circular, 101).

OLIVEIRA, I.P.; ARAÚJO, R.S.; DUTRA, L.G. Nutrição mineral e fixação biológica de nitrogênio. In: ARAÚJO, R.S.; RAVA, C.A.; STONE, L.F.; ZIMMERMANN, M.J. de O. (Coord.). Cultura do feijoeiro comum no Brasil. Piracicaba: Potafos, 1996. p.169-221.

PORTES, T.A. Ecofisiologia. In: ARAÚJO, R.S.; RAVA, C.A.; STONE, L.F.; ZIMMERMANN, M.J. de O. (Coord.). Cultura do feijoeiro comum no Brasil. Piracicaba: Potafos, 1996. p.101-137.

RAIJ, B. van; QUAGGIO, J.A. Métodos de análise de solo para fins de fertilidade. Campinas: Instituto Agronômico, 1983. 31p. (Boletim Técnico, 81).

ROSOLEM, C.A. Calagem e adubação mineral. In: ARAÚJO, R.S.; RAVA, C.A.; STONE, L.F.; ZIMMERMANN, M.J. de O. (Coord.). Cultura do feijoeiro comum no Brasil. Piracicaba: Potafos, 1996. p.353-390.

RYLE, G.J.A.; HESKETH, J.D. Carbon dioxide uptake in nitrogendeficient plants. Crop Science, v.9, p.451-454, 1969.

SILVA, T.R.B. da. Adubação nitrogenada e resíduos vegetais no desenvolvimento do feijoeiro (Phaseolus vulgaris L.) em sistema de plantio direto. 2002. 56p. Dissertação (Mestrado) - Universidade Estadual Paulista, Ilha Solteira.

SILVA, T.R.B. da; SORATTO, R.P.; CHIDI, S.N.; ARF, O.; SÁ, M.E. de; BUZETTI, S. Doses e épocas de aplicação de nitrogênio em cobertura na cultura do feijoeiro de inverno. Cultura Agronômica, v.9, p.1-17, 2000.

SILVEIRA, P.M. da; BRAZ, A.J.B.P.; DIDONET, A.D. Uso do clorofilômetro como indicador da necessidade de adubação nitrogenada em cobertura no feijoeiro. Pesquisa Agropecuária Brasileira, v.38, p.1083-1087, 2003.

SILVEIRA, P.M. da; DAMASCENO, M.A. Doses e parcelamento de K e de N na cultura do feijoeiro irrigado. Pesquisa Agropecuária Brasileira, v.28, p.1269-1276, 1993.

SORATTO, R.P.; SILVA, T.R.B. da; ARF, O.; CARVALHO, M.A.C. de. Níveis e épocas de aplicação de nitrogênio em cobertura no feijoeiro irrigado em plantio direto. Cultura Agronômica, v.10, p.89-99, 2001.

STONE, L.F.; SILVEIRA, P.M. da. Efeitos do sistema de preparo na compactação do solo, disponibilidade hídrica e comportamento do feijoeiro. Pesquisa Agropecuária Brasileira, v.34, p.83-91, 1999.

WUTKE, E.B. Adubação verde: manejo da fitomassa e espécies utilizadas no Estado de São Paulo. In: WUTKE, E.B.; BULISANE, E.A.; MASCARENHAS, H.A.A. (Coord.). Curso sobre adubação verde no Instituto Agronômico. Campinas: Instituto Agronômico, 1993. p.17-29. (Documentos, 35).

Recebido em 25 de março de 2004 e aprovado em 19 de agosto de 2004 